\title{
DRIVING FROM THE FRINGE INTO SPOTLIGHT \\ THE UNDERRATED ROLE OF STANDARDS AND STANDARDIZATION IN RTDI POLICY AND EVALUATION
}

\author{
ALFRED RADAUER \\ DOI: $10.22163 /$ fteval.2020.492
}

\section{INTRODUCTION}

I n an article of 2018 for the Japanese chapter of the AllPI (Association for the Protection of Intellectual Property of Japan), authors Yang \& Kim ask the rhetoric question what autonomous driving, artificial intelligence, blockchain, big data, and Internet of Things (IoT) all have in common. Their answer is that "they are disruptive, evolutionary, and affecting all of us" and, more importantly, that "... they also rely on... 'standards' - common protocols to ensure interoperability among our devices."

Standards - understood, according to the International Standard Organization (ISO), as documents produced "... by consensus and approved by a recognized body, that provides, for common and repeated use, rules, guidelines or characteristics for activities or their results, aimed at the achievement of the optimum degree of order in a given context" ${ }^{\text {"1 }}$ - are an important instrument in the toolbox of policy makers in various domains. Done the 'right' way, standards and the process leading to such standards (i.e., standardization) help to foster and diffuse innovations; to ensure economic competitiveness; as well as to allow for high safety, health and environmental protection levels when using products or services.

This general understanding is, however, a rather recent phenomenon. It is also reflected in the evolution of the research on standardization. For example, with respect to the important relationship between innovation and standardization, there were just 13 academic papers written on the subject in 1995 (Choi, et al., 2011). The number of papers on this topic henceforth increased constantly to around 70 publication p.a. some 15 years later. Despite the respective relevance of the topic, traditional RTDI policy has been treating the topic of standards \& standardization rarely as a topic of particular interest. In traditional depictions of the national innovation system, "standards and standardization" feature at the fringes, as part of the "infrastructure" of the system (Kuhlmann and Arnold, 2001).
National innovation system reviews rarely tackle the topic in adequate depth - the 2018 OECD review of the Austrian innovation policy, for example, mentions standardization only briefly in two places (OECD, 2018): first, with respect to $5 \mathrm{G}$ where it is said that the "standardization process is on-going" and that Austria, in terms of $5 \mathrm{G}$ deployment, is "...lagging in $5 G$ rollout behind leading countries such as Japan and Korea." (p. 118). In the second place, the statement is simply that some of Austria's ACR (Austrian Cooperative Research) institutes - "...are strongly involved in standardization activities at the national, European and international level." (p. 169). Most notably, there is no mention of standards and standardization in the chapter on the policy mix to support business R\&D and innovation. The OECD report hereby reflects that many countries, including Austria, do rarely have dedicated support mechanisms and programs in place to foster (quality) use and development of the standards and standardization system.

In this paper, we try to tackle this issue and discuss a) the evidence as it relates to the role of standards and standardization for research and innovation policy, and b) briefly outline possible reasons why the topic of standards and standardization may not receive the necessary attention. Furthermore, the paper presents an outline to policy developments and support mechanisms c) in place at the European level, d) at national level in Germany (which could be seen as being internationally, in Europe, in the lead in this field) and e) in Austria, all of which aim to improve the usage and development of standards. Eventually, the paper concludes by summarizing possible areas of action for policy makers and implementers as well as implications for evaluators of RTDI programs, institutions and policies. The paper is based on literature and document review complemented by three interviews conducted with an innovation agency and a standards-developing organization (SDO). ardization, importantly, apart from the policy instrument of government regulation. Government regulation makes the application of working principles laid out in the regulation mandatory by law.

2 ACR institutes denote a group of non-university private research institutes in Austria heavily involved with applied research for the benefit of SMEs (https:// www.acr.ac.at/english/, last accessed 5 0ctober 2020). 


\section{THE CURRENT EVIDENCE BASE REGARDING THE ECONOMIC IMPACT OF STANDARDS}

\subsection{BENEFITS AND EFFECTS}

A body of literature has developed over the past 20 years that tries to assess the economic impact of standards. Within those, a bulk of studies attempts to link macro-economic indicators (such as GDP, productivity) to the use of standards. Such studies draw on a production function that attempts to answer the question to what extent the output variables (e.g., GDP) can be attributed to the input variables (e.g., use of standards).

E.g., Blind, Jungmittag and Mangelsdorf (2012) use the Cobb-Douglas Production function which distinguishes as input variables capital input, workforce (labor input) and technical progress (otherwise also called total factor productivity). Technological progress is hereby the result of three components: technological knowledge generated within the country, technological knowledge created abroad and the diffusion of this knowledge. The big problem with this rather abstract function is to operationalize it with variables for which there exists empirical data. That data should, at least as proxies, reflect "technological creation" and "technological diffusion". In the said study Blind, Jungmittag and Mangelsdorf, use the number of patents filed over time in Germany and the licensing expenditures IP generated over time as proxies for the two knowledge generation variables. The number of standards created over time is utilized as proxy for knowledge dissemination.

Without divulging into a discussion on the advantages and deficiencies of using these specific variables for measuring what is supposed to be measured, the methodological approach highlights one significant aspect of current thinking about standards: as a channel for disseminating knowledge, for knowledge / technology transfer. This thinking pushes patents - otherwise a variable also widely discussed in terms of merits to measure technology transfer - somewhat back in a presumed "tech transfer value chain", as input variables. The authors state in this context (p. 4):

"To ensure continual economic growth it is not sufficient to only create new knowledge through research and development. This knowledge must also be broadly disseminated so that as many companies as possible can make use of it. Standards that are developed in consensus with the participation of companies are particularly suitable for disseminating technical knowledge. Standardization experts record the current technological standard in documents, thus facilitating its broad diffusion in the market. As opposed to information in patents, which are subject to intellectual property rights, the information codified in standards is accessible to all and therefore its dissemination is not restricted."

Using regression analysis, the analysis of Blind, Jungmittag and Mangeldsdorf suggests that standards may accrue an economic benefit in Germany of some $€ 16.77 b$ a year, corresponding to some $0.72 \%$ of Germany's GDP (time frame of the analysis: 1960 - 2006). Similar types of studies have been carried out for other countries, e.g. for the UK (Ho- gan et al, 2015) for the Nordic countries (Grimsby et al., 2018) (in both cases using labor productivity as dependent variables) or for Australia (Standards Australia, 2013). The results of all these studies point into the same direction.

Another body of studies, which is particularly interesting in the context of RTDI policy, looks at the interrelation between standards/standardization and innovation. To this end, comprehensive literature reviews of the available evidence have been carried out by Swann (Swann, 2010, updating earlier work of 2000) and, most recently, by Blind (2017). The table below provides a summary of effects: it can be seen that standards/standardization may have positive as well as negative effects on innovation.

Table 1 Functions of standards and their effects on innovation

\begin{tabular}{|c|c|c|}
\hline $\begin{array}{l}\text { Function of } \\
\text { standards }\end{array}$ & $\begin{array}{l}\text { Positive effects on } \\
\text { innovation }\end{array}$ & $\begin{array}{l}\text { Negative effects on } \\
\text { innovation }\end{array}$ \\
\hline \multirow{4}{*}{$\begin{array}{l}\text { Compatibility/ } \\
\text { interoperability }\end{array}$} & Network externalities & Monopoly power \\
\hline & $\begin{array}{l}\text { Avoiding lock-in to } \\
\text { old technologies }\end{array}$ & $\begin{array}{l}\text { Lock-in to old } \\
\text { technologies in case } \\
\text { of strong network } \\
\text { externalities }\end{array}$ \\
\hline & $\begin{array}{l}\text { Increasing variety } \\
\text { of system products }\end{array}$ & \\
\hline & $\begin{array}{l}\text { Efficiency in } \\
\text { supply chains }\end{array}$ & \\
\hline \multirow{3}{*}{$\begin{array}{c}\text { Minimum quality } \\
\text { / safety }\end{array}$} & $\begin{array}{l}\text { Avoiding adverse } \\
\text { selection }\end{array}$ & Raising rivals' costs \\
\hline & Creating trust & \\
\hline & $\begin{array}{l}\text { Reducing } \\
\text { transaction costs }\end{array}$ & \\
\hline \multirow{3}{*}{ Variety reduction } & Economies of scale & Reducing choice \\
\hline & $\begin{array}{l}\text { Critical mass } \\
\text { in emerging } \\
\text { technologies } \\
\text { and industries }\end{array}$ & $\begin{array}{c}\text { Market } \\
\text { concentration }\end{array}$ \\
\hline & & $\begin{array}{c}\text { Premature selection } \\
\text { of technologies }\end{array}$ \\
\hline Information & $\begin{array}{l}\text { Providing codified } \\
\text { knowledge }\end{array}$ & \\
\hline
\end{tabular}

Source: Blind (2017)

\subsection{BARRIERS}

Given the number of benefits one can accrue from standards and standardization, and in general the significance of standards for innovation, the question remains why standards / standardization are seemingly not getting more attention in RTDI policy making. A number of barriers are identifiable, among which the following stood out in discussions with interview partners during the writing of the paper:

- The fact that standards and standardization may have positive or negative effects on innovation may trigger a certain reluctance on the policy side to engage more with the topic. In interviews, we were provided with anecdotal evidence that this factor has played a role in the past in policy making in some countries when the question was for the competent authorities 
to place standards and standardization on the agenda. Indeed, finding the right balance in standards such that benefits are maximized while possible disadvantages (such as certification / compliance costs) are minimized is a key aspect policy makers and standards developers face. This challenge is faced also in adjacent policy areas, such as with the Intellectual Property (IP) system, where similarly good balances between the rights of right holders and non-right holders must be sought.

- There is clearly a lack of awareness on the processes and functions of standards and standardization, exacerbating the reluctance as noted in the bullet point above. In interviews, the need was expressed to address this issue with a variety of stakeholders and through a multitude of channels: in education, where teaching on standards and standards economics is scarce and patchy with relevant institutions; with researchers, who will have to do learning on the job when dealing with standards (provided they recognize their significance and potential when drafting the proposals); with policy makers and innovation support agencies, who may need handles on how to deal with this topic; etc.

- Connected to both items, there may be a perceived lack of 'sexiness' of the topic, according to interview evidence. Standards and standardization may be associated with rather dry and old topics and institutions which handle things like how plugs look like or what sizes sheets of paper should have. Too little may be known about the significant role of standardization in topics like Artificial Intelligence, e-mobility, sustainability, etc.

- The standards / standardization system has been repeatedly the subject of criticism in that it supposedly represents only (large) "insider" industry communities. Hence, there is a need to promote transparency and foster the participation of different stakeholder groups, including the research sector, SMEs, special interest groups (see also Blind, 2017).

- The standards / standardization system has been equally criticized for being rather slow, given that it requires consensus to be reached in the respective communities. In fact, there are examples where single industry participants have chosen to push ahead with own solutions rather than waiting for a standard to be established (one of the more recent examples was Apple's choice to develop its lightning connector (Müssig, 2020)). Apart from the fact that there are, conversely, also ample of success stories, SDOs (Standard Developing Organization; e.g., organizations like DIN) have developed sorts of "standards light" which can be developed faster and do not require full consensus. The respective instruments of "DIN specifications (DIN specs)" or the "CEN Workshop Agreement (CWA)" by the European standardization body CEN are to be mentioned in this context. They exemplify also instruments of the standardization system that may be particularly suitable for R\&D projects and also attainable within the running time of a project as project outputs.

\section{STANDARDIZATION AND INNOVATION SUPPORT - THE EUROPEAN DIMENSION}

At the European level there is considerable activity and support going on regarding standardization. However, it is arguable whether the majority of activities happen only within the standardization system and constitute actions to which classic innovation policy is mostly myopic. To mention is, first of all, that the European Commission is heavily involved in the development of standards, e.g. in the course of regulatory and law-making activities. There is clearly laid out work division between the $\mathrm{EC}$ and the three European standardization organizations (CEN - which brings together 33 national standard developing organizations generally for standards; CENELEC - specifically responsible for the electrotechnical engineering field; ETSI - for telecommunication), backed up also by law (Regulation 1025/2012). ${ }^{3}$

The system of harmonized standards should be highlighted at this point. ${ }^{4}$ These are European standards created by one of the said three European standardization bodies by request of the European Commission. Respective standards have been created in many technology fields, such as electric/electronic engineering (e.g., Low Voltage Directive, Radio Equipment Directive), toys (e.g., Toys Safety Directive), Medical Devices, Chemical substances (REACH), etc. The use of these standards remains voluntary, i.e. manufacturers, operators and conformity assessment bodies are free to choose to apply the standard for assessment of conformity with legal requirements or to use another technical solution.

Further to that, one can see also focal activities of the European Commission in certain areas of standardization. This is, for example, the development (and support of the development) of standards in the ICT sector; the area of making standards and standardization system more accessible to SMEs; or the activities around the topic of standard-essential patents (SEPS) and the respective licensing practices.

A key document in the context of the European standardization policy is the "Joint Initiative on Standardisation" from 2016, which is part of the Single Market Strategy. The Strategy „... sets out concrete actions to further drive innovation, raise awareness of the importance of standards, and improve the representation of European SMEs' interest internationally. ${ }^{\text {"5 }}$ The Initiative maps out various domains and defines activities within them (domain 1 being awareness and education; domain 2 being coordination, cooperation, transparency and inclusiveness; domain 3 concerns competitiveness and the international dimension). Some 15 actions have been defined within these domains. Notable among these are particularly the greater use of standards in public procurement (action 11); standardization to support digitization (action 14); improving the representation of SMEs and other stakeholders in the standardization process (action 15); programs for education in standardization/training and awareness (action 3), or - to be underlined particularly in the context of this article - linking research

3 https://ec.europa.eu/growth/single-market/european-standards_en, last accessed 3 November 2020

4 https://ec.europa.eu/growth/single-market/european-standards/harmonised-standards_en, last accessed 50 ctober 2020 
and innovation with standardization (action 2), which reads as follows (European Commission, 2016, p. 2):

"It is important to highlight the link between research, innovation and commercialisation using standardisation as early as possible in order to exploit to a maximum the outcomes of current and future research and innovation projects from, for example, Horizon2020 or from other existing technical platforms. An early in-depth analysis should be carried out of where, when and how standardisation can help to boost innovation in European innovation programs. It would also be helpful to increase the use of standards by business to foster market access for their innovation. Those standardisation deliverables supporting research and innovation projects that have been realised so far will be assessed and the development of pilot projects may also be taken into consideration."

A concrete activity that has evolved in this context are the BRIDGIT-I and BRIDGIT-II projects (BRIDGE - Bridging the Gap between Research and Standardization). The projects ran from 2013 to 2015 and then from 2017 to 2020 (BRIDIGIT-II will be hence closed soon). The aim was/is to „... overcome the barriers between the standardization world on one hand and on the other the European research and innovation community". BRIDGIT-II, as continuation of BRIDGIT-I, is co-funded by CEN-CENELEC and the EU/EFTA and assembles a number of national SDOs under the lead of DIN to a) increase the capacity of CEN-CENELEC member SDOs to engage with the RTDI community l, especially by participating in Horizon 2020 actions", Ibid.) and through mentoring programs/seminars; to support higher engagement of national SDOs with the local/national RTDI system; to assess the role of standardization in Framework Programs; to create a repository of tools for the RTDI community; to disseminate the results.

Against this backdrop, the project introduced the concept of an "integrated approach", which is outlined in a PDF document as a guide for SDOs on how to link standardization with (EU) research projects (CEN/ CENELEC, 2015). In essence, the integrated approach provides a) for rationales to advertise and evangelize the topic of standardization to research organizations and $\mathrm{b}$ ) provides for a process by which standardization is to be considered and integrated into R\&D projects. As - perhaps surprising - a core element of the process is the approach to have standardization bodies participate in R\&D projects as consortium partner.

This may look odd because one could assume that organizations like DIN, Austrian Standards International, etc. are public agencies like a patent office or an innovation agency. With such agencies, one would not expect participation in funded R\&D projects to be a strategic business case. The case of SDOs seems different. It must be remembered that SDOs are private organizations that operate under a different logic than public entities. In interviews, it was also revealed that SDOs may see their know-how of handling processes that lead to consensus among many discussants as an asset and business case beyond actual standardization.

The interviews have revealed that the majorly found operating mode for catering for the standardization topic in European research programs (Horizon Europe) is to have the topic clearly mentioned in call texts and working programs (e.g., as desirable outputs or outcomes). This should alert researchers to the significance of standardization for their proposals and the potential attractiveness of SDOs as consortia partners.

We were told in interviews that BRIDIGIT results indicate that, in this context, projects with SDO participation have been observed to have a higher chance of obtaining funding than projects without SDO participation. Against this backdrop, it is noteworthy that under the heading of what national standardization bodies can offer as a) "solution" to researchers preparing proposals as well as b) to national policy makers, it is said in the aforementioned "integrated approach": "...An appropriate integration of standardization can improve the results of the evaluation of project proposals and thus contribute to shares in European funds". (CEN/ CENELEC, 2015, p. 14). BRIDGIT and SDOs have created a number of case studies showing successful integration of the standardization topic in Horizon projects.

\section{$4 \quad$ RTDI COMMUNITIES AND STANDARDIZATION AT NATIONAL LEVELS}

\subsection{GERMANY}

Evaluators in the RTDI arena usually will hardly come across the topic of standardization in (national) RTDI funding, majorly because specific funding programs to foster the creation of standards rarely exist and the topic of standardization is mostly not catered for in "regular" support programs, at least not in a systematic way. The exception to that rule is Germany, where the Federal Ministry for Economic Affairs and Energy (BMWi) has been operating a respective support program for many years.

The support program WIPANO (WIssenstransfer durch PAtente und NOrmen, engl.: knowledge transfer through patents and standards) ${ }^{7}$ currently has one funding line (we denote this as funding line 1) where SMEs and firms (with up to 1,000 employees) can obtain a grant if they intend to start participating in standardization committees within SDOs. ${ }^{8}$ The funding is in the form of a grant that covers $70 \%$ of costs with a total ceiling of $€ 40,000$ per firm/project. The grant is payable in distinct installments ("Leistungspakete") which cover the following costs/areas: Advice concerning and actual participation in standardization committees (€20k max); searches on/within standards documentations (€10k max); development of a DIN Spec (€10k max). The maximum running time for funding line 1 is 36 months. This funding line has been only recently introduced.

The second funding line is specifically for technology transfer from university/research to industry. The funding concerns collaborative R\&D projects where at least one partner is a firm and a maximum of $70 \%$ of work (expressed in working time) is accounted for by universities or public research organizations (PROs). The projects are to focus on the transfer of R\&D results into standardization processes and, ultimately, the development of (drafts for) new standards. Universities and PROs

6 https://www.din.de/en/innovation-and-research/research-projects/innovation-and-education/bridgit2-276692, last accessed 5 0ctober 2020

7 https://www.innovation-beratung-foerderung.de/INNO/Navigation/DE/WIPANO/wipano.html, last accessed 50 ctober 2020

8 The exact requirement is that the firms should not have engaged in standardization committees in the past three years. 
can have $85 \%$ of their costs covered, participating SMEs up to $80 \%$. The running time of the respective projects is set at a maximum of 24 months. This funding line has been in existence in varied forms and under different names since around 2006.

WIPANO has been regularly evaluated - its predecessor programs date back to the early 2000 years -, with the most recent evaluation having been undertaken by Fraunhofer ISI in 2019 (Kulicke et al., 2019). The evaluation concerned the entire WIPANO program, not only the funding lines for standards. As regards the standards funding lines, the major results were the following:

- At the time of the evaluation, the number of funded projects in the SME funding line (funding line 1) was still considered rather low, due also to a longer design and preparation phase for setting up the current form of the funding scheme. Between 2016 and end of 2018, WIPAN0 approved funding in both funding lines for a total of 172 projects and granted $€ 16.75 \mathrm{~m}$ to the various firms and consortia members.

- $66 \%$ of the beneficiaries were firms, $34 \%$ universities/PROs. $31 \%$ of beneficiaries were SMEs, which is regarded as a success, which could be, however, still enhanced. Both funding lines address a specialist community, where standards and standardization play a significant role. Awareness of the funding possibilities outside of this core interest group was regarded as low and is hence an area of improvement.

- In order to increase visibility and awareness, the evaluation suggests addressing specifically experts with experience in technological fields and presumably working in contexts close to the topic of standardization.

- The authors also suggest a number of measures to increase the attractiveness of the program for SMEs, however, also to wait a bit longer with specific measures until further project results materialize. Generally, though, the evaluators underline the need for a specific funding scheme for SMEs as implemented with funding line 1.

In interviews, we were also told that due to regulatory requirements, funding line 2 had to be modified over time such that it would only support larger projects. This has opened a gap for smaller undertakings, which is closed by a funding scheme offered by DIN itself called DIN Connect. DIN Connect has as target SMES and start-ups with innovative project ideas and with potential for standards and standardization.

Overall, all funding activities are embodied into a national standards strategy, the so-called "Normungspolitisches Konzept" (BMWi, 2009; due to be updated).

\subsection{AUSTRIA}

In contrast to Germany, there are no dedicated funding mechanisms in Austria to support standards in R\&D projects. However, there is a strategy for standardization in place from March 2016 which defines six goals with corresponding action lines (Austrian government, 2016): a) Policy advice through a steering committee; b) fostering of transparency and participation in standardization; c) contributions to European/ international standardization; d) strengthening of competitiveness and support for RTDI; e) contribution to sustainability goals; and f) support as well as complementary action for government regulatory activities.
The strategy specifies a series of activities to increase awareness on the topic (including also the inclusion of standardization into curricula of relevant educational institutions) as well as a call for early consideration of standardization in research projects and in the dissemination / transfer of research results.

The question remains, though, whether this specific strategy is taken duly into consideration in RTDI policy making. The OECD Innovation Policy Review of Austria suggests that this is rather not the case, and the current Austrian RTDI strategy mentions standardization only superficially in few places (Austrian government, 2011). Still, the aspiration is there with Austrian Standards International, the Austrian SDO, to play a stronger role in the Austrian RTDI system. This is underlined by placing the topic of innovation prominently on its homepage, by engaging heavily with the BRIDIGIT project and hereby also involving actors from the RTDI community - most notably, Austria's research promotion agency FFG. However, in interviews it was consensus that this is only the beginning of a journey.

\section{CONCLUSIONS AND RECOMMENDATIONS}

This paper has sought to analyze the topic of standardization and standards in relation to the RTDI system. While it has shown that attempts are being made to literally bridge the gap between the two worlds, it is also clear that more spotlight on the standards topic is needed to reap the potential benefits when innovating and supporting innovation. Recommendations go towards both the researcher/evaluation community as well as to policy makers and implementers:

- Researchers and evaluators should seek to address the topic of standardization and standards more pro-actively. While increasing ground has been covered by scholars on the basic picture regarding economic impacts of standards, there is need for more granular evidence, particularly in fields like open innovation research (where it is easily understandable that standardization can be seen as a form of open innovation, yet this seems to be hardly reflected in open innovation literature) or technology and knowledge transfer research. In the context of the latter, the topic of indicator development seems a particularly pristine field. For example, the still valid Commission recommendation of 2008 on the management of intellectual property in knowledge transfer activities discusses a variety of channels for technology transfer, but not standards or contributions to standardization (European Commission, 2008). The EC Expert Group on Metrics for Knowledge Transfer from universities and Public Research Organizations (PROs) suggests and discusses numerous indicators, none of which with a link to standards or standardization (European Commission, 2009). Given that the macro-economic models as discussed in this paper treat "standards" specifically as a channel for knowledge transfer, this is truly surprising and - in terms of consistency within innovation research - actually concerning. Starting points are e.g. developments such as the concept of standard-relevant publications in bibliometrics (Blind, 2019).

- The RTDI and standards policy developer and implementer should more strongly collaborate with each other, also outside 
of dedicated projects like Bridgit. There is most likely a need, not only at European, but also at national level, to discuss how standards and standardization can be better integrated in innovation policy/strategy and program designs (such as by wording of specific standards' related goals of innovation policy in key technology areas, where relevant); in the way standards and contributions to standards should be handled and assessed in appraisals of R\&D proposals. There needs to be a clearer understanding of a possible and good role of SDOs and hence better integration of these organizations in the RTDI systems, moving them from the fringes of the cast of actors in the innovation systems into appropriately more central places. Similarly, SDOs and actors of the standardization system must also build capacity for understanding the functioning of RTDI systems and their actors more profoundly. Mutual exchanges, awareness raising and also examining possible good practices (such as the WIPANO funding schemes in Germany) are here the starting points.

\section{REFERENCES}

Austrian government (2011): Austrian RTI Strategy, https://www.bmk. gv.at/themen/innovation/publikationen/fti_strategie.html, last accessed 5 October 2020

Austrian government (2016): Austrian Strategy for Standards and Standardisation ("Österreichische Normungsstrategie"), https://www. bmdw.gv.at/Themen/Technik-und-Vermessung/Normung.html, last accessed 5 0ctober 2020

Blind, K. (2017): The economic functions of standards in the innovation process, in: Hawkins, R., Blind, K. \& Page, R. (2017): Handbook of Innovation and Standards

Blind, K. (2019): DIE BESTEN DREI ZUR VERWERTUNG - Vergleich der Strategie-Trias für Wissenschaft, Forschung und Entwicklung (F\&E), in: Wissenschaftsmanagement 2/2019, https://www.wissenschaftsmanagement.de/dateien/k2_wima_2_2019_cases_blind.pdf, last accessed 5 October 2020

Blind, K., Jungmittag, A. and Mangelsdorf, A. (2012): The economic benefits of standardisation. An update of the study carried out by DIN in 2000 .

BMWi (2009): Normungspolitisches Konzept, https://www.bmwi.de/ Redaktion/DE/Downloads/M-0/normungspolitisches-konzept-der-bundesregierung.pdf?_blob=publicationFile $\mathscr{G V}=3$, last accessed 5 0ctober 2020

CEN / CENELEC (2015): How to link standardization with EU research projects. https://www.cencenelec.eu/research/news/publications/Publications/BRIDGIT-members-guide.pdf, last accessed 3 November 2020. Choi, D. G., Lee, H., and Sung, T. K. (2011). Research profiling for 'standardization and innovation'. Scientometrics, 88(1), 259-278.
European Commission (2008): COMMISSION RECOMMENDATION on the management of intellectual property in knowledge transfer activities and Code of Practicefor universities and other public research organisations communities

European Commission (2009): Metrics for Knowledge Transfer from Public Research Organisations in Europe - Report from the European Commission's Expert Group on Knowledge Transfer Metrics

European Commission (2016): Proposals for a first draft set of actions and pilot projects under the Joint Initiative for Standardisation

Grimsby, et al. (2018): THE INFLUENCE OF STANDARDS ON THE NORDIC ECONOMIES, https://www.menon.no/wp-content/uploads/201831-Nordic-market-study-influence-of-standards.pdf, last accessed 5 October 2020

Hogan, 0., Sheehny, C., and Jayasuriya, R. (2015): The Economic Contribution of Standards to the UK Economy: 2015. British Standards Institution.

Kuhlmann, S. and E. Arnold (2001): RCN in the Norwegian research and innovation system.

Kulicke, M., Meyer, N., Stahlecker, T. and Jackwerth, T. (2019). Evaluation des Programms WIPANO - "Wissens-und Technologietransfer durch Patente und Normen" Studie im Auftrag des Bundesministeriums für Wirtschaft und Energie. 10.13140/RG.2.2.34397.97761.

Müssig, F. (2020): USB-Entwickler über Apples Lightning-Stecker: "Wir waren zu träge", in: heise online, https://heise.de/-4645413, last accessed 5 October 2020

OECD (2018): OECD Reviews of Innovation Policy: Austria 2018, OECD Reviews of Innovation Policy, OECD Publishing, Paris, https://doi. org/10.1787/9789264309470-en.

Standards Australia (2013): The Economic Benefits of Standardisation, https://www.standards.org.au/StandardAU/Media/SA-Archive/OurOrganisation/News/Documents/Economic-Benefits-of-Standardisation. pdf, last accessed 5 October 2020

Swann, P.W. (2010): The Economics of Standardization: An Update. https://citeseerx.ist.psu.edu/viewdoc/download?doi=10.1.1.618.5922\&r ep=rep 1 \&type $=p d$, last accessed 5 0ctober 2020

Yang, M.T. and Kim, J. (2018): Managing the Unavoidable-Recent Developments in Standard Essential Patent Litigation in the U.S. and Europe. AIPPI Japan. https://www.finnegan.com/en/insights/articles/ managing-the-unavoidablerecent-developments-in-standard-essentialpatent-litigation-in-the-us-and-europe.html, last accessed 3 November 2020. 


\section{AUTHOR}

\section{ALFRED RADAUER}

IMC Fachhochschule Krems

IMC University of Applied Sciences Krems

Piaristengasse 1, 3500 Krems, Austria

E: alfred.radauer@fh-krems.ac.at

ORCID 0000-0002-0489-2785

\section{Acknowledgments}

The author would like to thank Mr. Karl Grün (Austrian Standards); Mrs. Andrea Höglinger (FFG); Mrs. Katja Krüger; Mr. Mario Beier (both DIN) for having agreed to be interviewed. Similarly, the author would like to thank Harald Grill (Technopolis) for providing important feedback.

\section{KEYWORDS}

Standards, Standardization, Intellectual Property, IPR, Innovation, Innovation Policy 